\title{
Menopause rating scale: a simple tool for assessment of climacteric symptoms
}

\author{
Ramya N. R., Radhika Gadgi*
}

Department of Obstetrics and Gynaecology, Yenepoya Medical College Hospital, Mangalore, Karnataka, India

Received: 05 September 2020

Accepted: 21 September 2020

\author{
*Correspondence: \\ Dr. Radhika Gadgi, \\ E-mail: drradhikam123@gmail.com
}

Copyright: ( ) the author(s), publisher and licensee Medip Academy. This is an open-access article distributed under the terms of the Creative Commons Attribution Non-Commercial License, which permits unrestricted non-commercial use, distribution, and reproduction in any medium, provided the original work is properly cited.

\begin{abstract}
Background: Menopause is a physiological event, a unique stage of a female reproductive system and transition in life that occurs in all women who reach midlife. The clinical consequence of menopause is due to estrogen deficiency. Some of menopausal symptoms experienced by these women can be severe enough to affect their normal lifestyle. Unfortunately, majority of these women are not aware of the changes brought about by menopause. Objective of the study was to assess the prevalence of different menopausal symptoms and their severity according to menopause rating scale and their impact on quality of life.

Methods: A cross sectional study was conducted by the department of obstetrics and gynaecology, Yenopaya Medical College, Mangalore between June 2020 to August 2020. A total of 210 women who are between the age of 40 and 65 years who had their last menstrual period of at least 1 year ago and were included in the study.

Results: In the study majority of subjects were in the age group 46 to 50 years $(42.9 \%)$. In the study there was significant association between general health and hot flushes, heart discomfort, depressive mood, irritability, physical and mental exhaustion, bladder problems and joint and muscular pain. There was no significant association between general health and sleep problem, anxiety, sexual problems and dryness of vagina.

Conclusion: The menopausal rating scale can be used an effective tool while examining the patients for menopausal symptoms. Regular screening of such women can make a huge difference, and their quality of life can be improved.
\end{abstract}

Keywords: Menstruation, Scale, Hot flusher, Women, Reproductive age

\section{INTRODUCTION}

Modern medicine has significantly prolonged women lifespan. ${ }^{1}$ All women who live long enough will make transition to menopause. ${ }^{2}$ Menopause is defined as the permanent cessation of menstruation for 12 months or more as a result of ovarian failure, occurs at an average age of 52 years with a range of 40 to 58 years. In the current scenario with the better availability of health services the life expectancy has increased, and as result the women are more likely to spend a significant part of their life during this phase of menopause. ${ }^{3}$

Menopause is a physiological event, a unique stage of a female reproductive system and transition in life that occurs in all women who reach midlife. Menopause is associated with changes in hypothalamus and pituitary hormones that regulate the menstrual cycle; menopause is not central event but rather an indication of primary ovarian failure. At the level of ovary there is depletion of ovarian follicles, secondary to apoptosis or programmed cell death. The ovary is no longer able to respond to the pituitary's follicle stimulating hormone (FSH) and luteinizing hormone (LH) and ovarian estrogen and progesterone production ceases. The uterus and the vagina gradually become atrophic. As the negative feedback effect of reduced estrogen and progesterone, secretion of FSH, LH is increased. 
The clinical consequence of menopause is due to estrogen deficiency. This is associated with hot flushes, sweating and vaginal dryness. Many other symptoms like restless legs, muscle and joint pain, palpitation, forgetfulness, depressed mood, osteoporosis and dyslipidaemia are associated with menopause although these may not all be directly related to estrogen lack. These can be grouped into vasomotor, physical, psychological or sexual complaints. Some of menopausal symptoms experienced by these women can be severe enough to affect their normal lifestyle. Unfortunately, majority of these women are not aware of the changes brought about by menopause. ${ }^{4}$ It is well documented that menopausal symptoms experienced by women affect their quality of life. $^{5}$

Worldwide, the estimates for the mean age of menopause range from 40-65 years. The average age of menopause in Indian women is 47.5 years according to Indian Menopause Society (IMS) research which is much less than their western counter parts (51 years). So, menopausal health demands even higher priority in Indian scenario. ${ }^{6}$ Menopause has also been looked on as a signal occurring at the right time of life when preventive healthcare is crucial. The primary aim of health promotion is improvement of quality of life (QOL). Assessment of QOL at menopause has been largely inadequate. ${ }^{7}$ Despite evidence of psychosocial distress, the level of development and evaluation of QOL is poor in the gynecology outpatient clinics. Among the various commonly used scales to assess menopause, the final menopause rating scale (MRS) is the health-related quality of life scale comprises of 11 symptoms each rated on a five-point scale of severity. ${ }^{8}$

The intensity of menopausal symptoms within a given population varies depending on several factors like age, socio demographic profile, and educational level and working or non-working status. This study contains data collected from Indian post-menopausal women to get a first comprehensive picture of psychometric and other methodological characteristics of the MRS. This scale was designed and standardized to assess symptoms/ complaints of women who have attained menopause. The interest of clinical research on aging women has increased in recent years and thereby the interest to measure their health-related quality of life has also increased.

Objective of the study was to assess the prevalence of different menopausal symptoms and their severity according to MRS and their impact on quality of life.

\section{METHODS}

A cross sectional study was conducted among women aged between 40 to 65 years of age who attended the
OPD in the department of obstetrics and gynaecology, Yenopaya Medical College, Mangalore between June 2020 to August 2020. With the clinical experience, it is confirmed that approximately $20 \%$ of women among the women who attained menopause experience menopausal symptoms. With 5\% level of significance and with $10 \%$ precision, $n=183$ rounded to 210 . Hence the sample size was estimated for the study was 210 .

Inclusion criteria included women who are between the age of 40 and 65 years who had their last menstrual period of at least 1 year ago and presenting to outpatient department of obstetrics and gynaecology of Yenepoya Medical College, Mangalore and who consented for voluntary participation are included.

Exclusion criteria excluded women who had undergone hysterectomy, taking contraception, with acute and chronic illness and women with recall bias.

Statistical analysis, data was entered into Microsoft excel data sheet and was analysed using SPSS 22 version software. Categorical data was represented in the form of frequencies and proportions. Chi-square test was used as test of significance for qualitative data.

For the graphical representation of data, MS Excel and MS word was used to obtain various types of graphs such as bar diagram. $\mathrm{P}$ value (Probability that the result is true) of $<0.05$ was considered as statistically significant after assuming all the rules of statistical tests.

Statistical software like MS Excel, SPSS version 22 (IBM SPSS Statistics, Somers NY, USA) was used to analyse data.

\section{RESULTS}

Mean age at menopause was $47.36 \pm 4.30$ year and mean age at menarche was $13.51 \pm 1.16$ years. In study majority of subjects were in age group 46 to 50 years $(42.9 \%)$, $74.3 \%$ were married, $24.3 \%$ were widowed, majority of them were illiterate $(34.4 \%), 68.6 \%$ belonged to lower socioeconomic status, majority attained menarche at age of 14 years $(32.9 \%)$, $55.7 \%$ had $>2$ children, $38.6 \%$ had gynaecologist check-up and $74.3 \%$ had good general health and $25.7 \%$ had poor general health. In study $34.3 \%$ were illiterate and $65.7 \%$ were literate.

In the study $50 \%$ of subjects had hot flushes, $44.3 \%$ had heart discomfort, $62.9 \%$ had sleep problem, $52.9 \%$ had depressive mood, $57.1 \%$ had irritability, $58.6 \%$ had anxiety, $68.6 \%$ had physical and mental exhaustion, $50 \%$ had sexual problems, $40 \%$ had bladder problems, $44.3 \%$ had dryness of vagina and $88.6 \%$ had joint and muscular pain. 


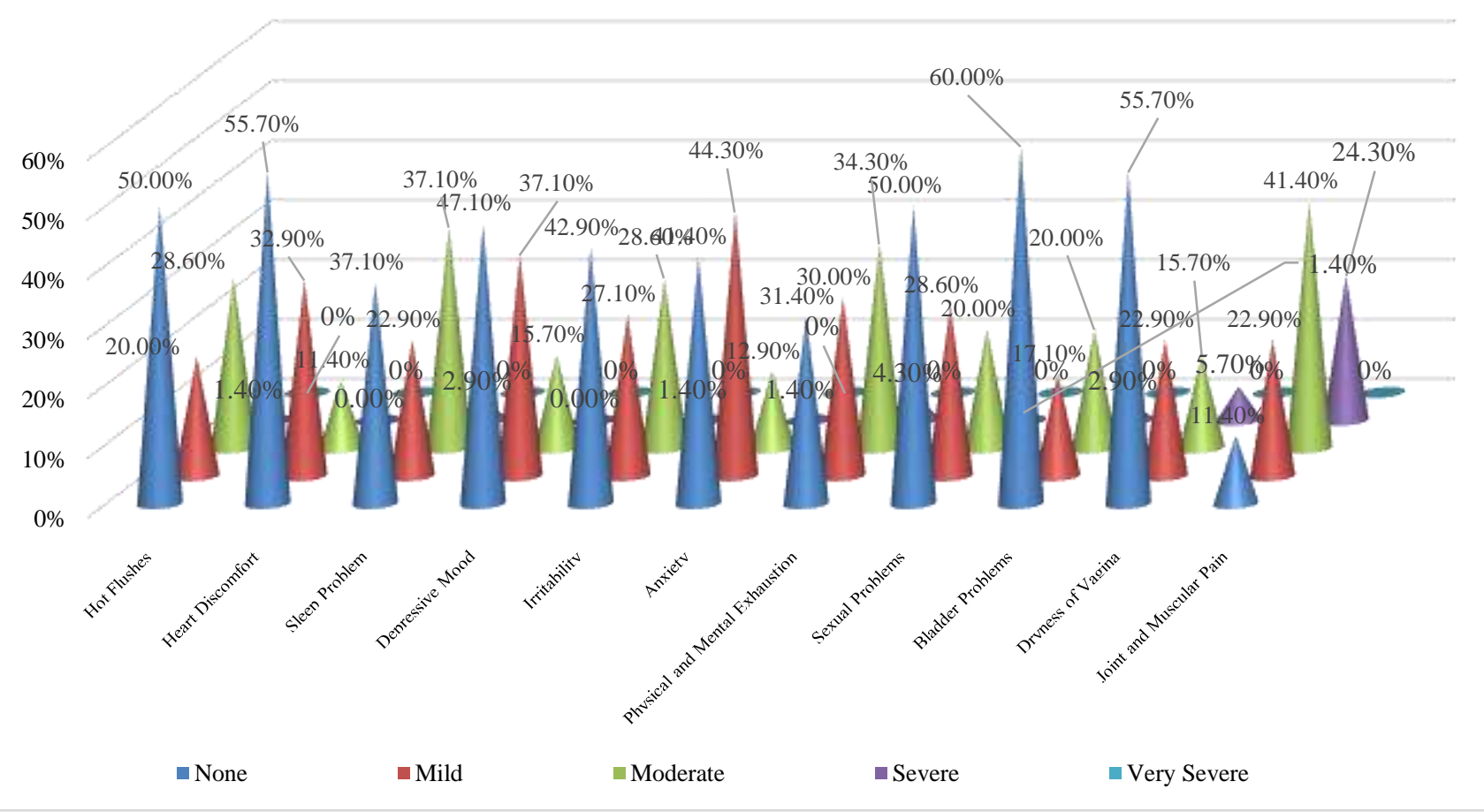

Figure 1: Bar diagram of menopause symptoms using MRS.

Table 1: Profile of subjects in the study.

\begin{tabular}{|c|c|c|c|}
\hline Variables & & Count & Percentage (\%) \\
\hline \multirow{5}{*}{ Age at Menopause (Years) } & 40 to 45 & 75 & 35.7 \\
\hline & 46 to 50 & 90 & 42.9 \\
\hline & 51 to 55 & 39 & 18.6 \\
\hline & 56 to 60 & 6 & 2.9 \\
\hline & 61 to 65 & 0 & 0.0 \\
\hline \multirow{3}{*}{ Marital status } & Divorced & 3 & 1.4 \\
\hline & Married & 156 & 74.3 \\
\hline & Widowed & 51 & 24.3 \\
\hline \multirow{4}{*}{ Education status } & Illiterate & 72 & 34.3 \\
\hline & Primary & 63 & 30.0 \\
\hline & Secondary & 63 & 30.0 \\
\hline & Tertiary & 12 & 5.7 \\
\hline \multirow{3}{*}{ Socioeconomic status } & Lower & 144 & 68.6 \\
\hline & Middle & 66 & 31.4 \\
\hline & Upper & 0 & 0 \\
\hline \multirow{6}{*}{ Age at menarche (years) } & 11 & 9 & 4.3 \\
\hline & 12 & 33 & 15.7 \\
\hline & 13 & 57 & 27.1 \\
\hline & 14 & 69 & 32.9 \\
\hline & 15 & 36 & 17.1 \\
\hline & 16 & 6 & 2.9 \\
\hline \multirow{2}{*}{ Number of children } & $<2$ & 93 & 44.3 \\
\hline & $>2$ & 117 & 55.7 \\
\hline \multirow{2}{*}{ Gynaecologist check up } & No & 129 & 61.4 \\
\hline & Yes & 81 & 38.6 \\
\hline \multirow{2}{*}{ General health } & Good & 156 & 74.3 \\
\hline & Poor & 54 & 25.7 \\
\hline
\end{tabular}


Table 2: Menopause symptoms using MRS.

\begin{tabular}{|c|c|c|c|c|c|c|c|c|c|c|}
\hline \multirow[t]{2}{*}{ Symptoms } & \multicolumn{2}{|c|}{ None } & \multicolumn{2}{|c|}{ Mild } & \multicolumn{2}{|c|}{ Moderate } & \multicolumn{2}{|c|}{ Severe } & \multicolumn{2}{|c|}{ Very severe } \\
\hline & $\mathrm{C}^{*}$ & $\%$ & $\mathrm{C}$ & $\%$ & $\mathbf{C}$ & $\%$ & $\mathbf{C}$ & $\%$ & $\mathbf{C}$ & $\%$ \\
\hline Hot flushes & 105 & 50.0 & 42 & 20.0 & 60 & 28.6 & 3 & 1.4 & 0 & 0 \\
\hline Heart discomfort & 117 & 55.7 & 69 & 32.9 & 24 & 11.4 & 0 & 0.0 & 0 & 0 \\
\hline Sleep problem & 78 & 37.1 & 48 & 22.9 & 78 & 37.1 & 6 & 2.9 & 0 & 0 \\
\hline Depressive mood & 99 & 47.1 & 78 & 37.1 & 33 & 15.7 & 0 & 0.0 & 0 & 0 \\
\hline Irritability & 90 & 42.9 & 57 & 27.1 & 60 & 28.6 & 3 & 1.4 & 0 & 0 \\
\hline Anxiety & 87 & 41.4 & 93 & 44.3 & 27 & 12.9 & 3 & 1.4 & 0 & 0 \\
\hline Physical and mental exhaustion & 66 & 31.4 & 63 & 30.0 & 72 & 34.3 & 9 & 4.3 & 0 & 0 \\
\hline Sexual problems & 105 & 50.0 & 60 & 28.6 & 42 & 20.0 & 3 & 1.4 & 0 & 0 \\
\hline Bladder problems & 126 & 60.0 & 36 & 17.1 & 42 & 20.0 & 6 & 2.9 & 0 & 0 \\
\hline Dryness of vagina & 117 & 55.7 & 48 & 22.9 & 33 & 15.7 & 12 & 5.7 & 0 & 0 \\
\hline Joint and muscular pain & 24 & 11.4 & 48 & 22.9 & 87 & 41.4 & 51 & 24.3 & 0 & 0 \\
\hline
\end{tabular}

Table 3: Severity as per MRS and their impact on quality of life.

\begin{tabular}{|c|c|c|c|c|c|c|}
\hline \multirow{3}{*}{ Symptoms } & & \multicolumn{4}{|c|}{ General health } & \multirow{3}{*}{ P value } \\
\hline & & \multicolumn{2}{|c|}{ Good } & \multicolumn{2}{|l|}{ Poor } & \\
\hline & & Count & $\%$ & Count & $\%$ & \\
\hline \multirow{4}{*}{ Hot flushes } & 0 & 81 & 51.9 & 24 & 44.4 & \multirow{4}{*}{$0.018 *$} \\
\hline & 1 & 33 & 21.2 & 9 & 16.7 & \\
\hline & 2 & 42 & 26.9 & 18 & 33.3 & \\
\hline & 3 & 0 & 0.0 & 3 & 5.6 & \\
\hline \multirow{3}{*}{ Heart discomfort } & 0 & 96 & 61.5 & 21 & 38.9 & \multirow{3}{*}{$0.015^{*}$} \\
\hline & 1 & 45 & 28.8 & 24 & 44.4 & \\
\hline & 2 & 15 & 9.6 & 9 & 16.7 & \\
\hline \multirow{4}{*}{ Sleep problem } & 0 & 60 & 38.5 & 18 & 33.3 & \multirow{4}{*}{0.222} \\
\hline & 1 & 39 & 25.0 & 9 & 16.7 & \\
\hline & 2 & 54 & 34.6 & 24 & 44.4 & \\
\hline & 3 & 3 & 1.9 & 3 & 5.6 & \\
\hline \multirow{3}{*}{ Depressive mood } & 0 & 78 & 50.0 & 21 & 38.9 & \multirow{3}{*}{$<0.001 *$} \\
\hline & 1 & 66 & 42.3 & 12 & 22.2 & \\
\hline & 2 & 12 & 7.7 & 21 & 38.9 & \\
\hline \multirow{4}{*}{ Irritability } & 0 & 69 & 44.2 & 21 & 38.9 & \multirow{4}{*}{$0.014 *$} \\
\hline & 1 & 48 & 30.8 & 9 & 16.7 & \\
\hline & 2 & 36 & 23.1 & 24 & 44.4 & \\
\hline & 3 & 3 & 1.9 & 0 & 0.0 & \\
\hline \multirow{4}{*}{ Anxiety } & 0 & 66 & 42.3 & 21 & 38.9 & \multirow{4}{*}{0.578} \\
\hline & 1 & 69 & 44.2 & 24 & 44.4 & \\
\hline & 2 & 18 & 11.5 & 9 & 16.7 & \\
\hline & 3 & 3 & 1.9 & 0 & 0.0 & \\
\hline \multirow{4}{*}{$\begin{array}{l}\text { Physical and mental } \\
\text { exhaustion }\end{array}$} & 0 & 54 & 34.6 & 12 & 22.2 & \multirow{4}{*}{$0.004 *$} \\
\hline & 1 & 51 & 32.7 & 12 & 22.2 & \\
\hline & 2 & 48 & 30.8 & 24 & 44.4 & \\
\hline & 3 & 3 & 1.9 & 6 & 11.1 & \\
\hline \multirow{4}{*}{ Sexual problems } & 0 & 78 & 50.0 & 27 & 50.0 & \multirow{4}{*}{0.745} \\
\hline & 1 & 45 & 28.8 & 15 & 27.8 & \\
\hline & 2 & 30 & 19.2 & 12 & 22.2 & \\
\hline & 3 & 3 & 1.9 & 0 & 0.0 & \\
\hline \multirow{4}{*}{ Bladder problems } & 0 & 99 & 63.5 & 27 & 50.0 & \multirow{4}{*}{$<0.001 *$} \\
\hline & 1 & 27 & 17.3 & 9 & 16.7 & \\
\hline & 2 & 30 & 19.2 & 12 & 22.2 & \\
\hline & 3 & 0 & 0.0 & 6 & 11.1 & \\
\hline \multirow{4}{*}{ Dryness of vagina } & 0 & 90 & 57.7 & 27 & 50.0 & \multirow{4}{*}{0.743} \\
\hline & 1 & 33 & 21.2 & 15 & 27.8 & \\
\hline & 2 & 24 & 15.4 & 9 & 16.7 & \\
\hline & 3 & 9 & 5.8 & 3 & 5.6 & \\
\hline
\end{tabular}

Continued. 


\begin{tabular}{|c|c|c|c|c|c|c|}
\hline \multirow{3}{*}{ Symptoms } & & \multicolumn{4}{|c|}{ General health } & \multirow{3}{*}{ P value } \\
\hline & & Good & & Poor & & \\
\hline & & Count & $\%$ & Count & $\%$ & \\
\hline \multirow{4}{*}{ Joint and Muscular pain } & 0 & 18 & 11.5 & 6 & 11.1 & \multirow{4}{*}{$0.001 *$} \\
\hline & 1 & 45 & 28.8 & 3 & 5.6 & \\
\hline & 2 & 63 & 40.4 & 24 & 44.4 & \\
\hline & 3 & 30 & 19.2 & 21 & 38.9 & \\
\hline
\end{tabular}

*P value.

In the study there was significant association between general health and hot flushes, heart discomfort, depressive mood, irritability, physical and mental exhaustion, bladder problems and joint and muscular pain. There was no significant association between general health and sleep problem, anxiety, Sexual Problems and dryness of vagina.

\section{DISCUSSION}

The Greek word climacteric means steps of ladder which can be compared with women age and her characteristics. its long known since ages that from the time of birth till the menopause the women will be under the influence of numerous hormones which will help her to pass through all the phase of her life from childhood to fertile period to Menopause. Majority of the symptoms and signs are either directly or indirectly related to effect of the estrogens in the body.

Ageing is inevitable phenomenon and with it are associated certain conditions which affect quality of life.

Menopause is such reality of life. The mean age at menopause in this study was 47.3 years which can be compared to the study findings of Khatoon et al $(50.33$ years). ${ }^{3}$ The average age of menopause in Indian population set up is found to be around 47.5 years and different parts of the world ranging from 48 to 51 years which is similar to this study findings. ${ }^{3,9}$

The quality of life in the old age depends upon the socioeconomic condition of every individual. In this study the menopausal symptoms were found to be more common among the women who belong to the lower socioeconomic strata and also among the subjects who had No formal education. In the study done by Lee et al the socio economic condition and the education of the study subjects were often related and the people with low socio economic status and no formal education were commonly affected by the menopausal symptoms which is similar to this study findings. ${ }^{10}$ In the study done by Kakkar et al and Del Pardo et al also showed that women with lesser education status and low socio economic condition are most commonly affected by menopausal symptoms. ${ }^{11,12}$ Where as in the study done by Joseph et al the findings of this study were contrary to this study findings where women having formal education had more menopausal symptoms. ${ }^{13}$
On evaluating the presence of various menopausal symptoms among the study subjects we found that all most all the symptoms were either ranging from mild to moderate and none of them had experienced any kind of severe illness. Among various symptoms involvement of joints and muscular pain $(88.6 \%)$ was found to be most commonly affected system followed by physical and mental exhaustion (68.6\%), disturbed sleep (62.9\%) and anxiety $(58.6 \%)$ in this study. The classical symptoms of menopause like hot flushes, sweating and dryness of vagina was also seen in more than $40 \%$ of the study subjects.

In the study done by Khatoon et al, Cheng et al and Hafiz et al the most common symptoms were joint and muscular pain which is similar to this study findings. ${ }^{3,14,15}$ In the study done by Rahaman et al also the most common findings were involving musculoskeletal system followed by classical symptoms of menopause in nearly $41.6 \%$ of the study subjects which is similar and comparable to this study findings. ${ }^{3}$ In another study done by Yanikkerem et al the vasomotor symptoms were found to be most common symptoms in menopause than musculoskeletal system. ${ }^{16}$ In the study done by Pal et al the physical and mental exhaustion was found to be much more common than other symptoms.

On comparing various studies done by different authors in different parts of the world the menopausal symptoms are found to be ranging from mild to moderate and each study have found different symptoms to be most common menopausal symptoms. This wide variation in the presenting complaints of the menopause symptoms depends of lot of socio demographic factors, socio cultural factors and the tradition and cultural and lifestyle of the persons.

Similarly, in this study also these most common presentations of menopausal symptoms were found to be significantly associated with the quality of the life of the women.

\section{CONCLUSION}

The menopausal rating scale can be used an effective tool while examining the patients for menopausal symptoms. The phase of life i.e. menopause which brings lot of physical, emotional, hormonal and social changes to women's life can be better prepared and coped with reduced burden on the women with prop we and adequate 
health care facility by self-evaluating this tool. It helps in the smooth transition of women life from reproductive to old age. Women should be educated through awareness programs so that they can get proper medical attention. Health professionals should also assess the symptoms with a standard tool. Regular screening of such women can make a huge difference, and their quality of life can be improved.

Funding: No funding sources

Conflict of interest: None declared

Ethical approval: The study was approved by the Institutional Ethics Committee

\section{REFERENCES}

1. Changa MH, Wangb SJ, Wanga PH, Fuhd JL. Attitudes towards Menopause among Middle-Aged Women: A Community Survey in an Island of Taiwan. Maturitas. 2005;52(3-4):348-55.

2. Wang SJ, Lue SR, Juang KD, Chiu LM. The Kinmen women-health investigation (kiwi): a menopausal study of and population aged 40-54. Maturitas. 2001;39:117-20.

3. Khatoon F, Sinha P, Shahid S, Gupta U. Assessment of menopausal symptoms using modified menopause rating scale (MRS) in women of Northern India. Int J Reprod Contracept Obst Gynecol. 2018;7(3):947-51.

4. Rahman S, Salehin F, Iqbal A. Menopausal symptoms assessment among middle age women in Kushtia, Bangladesh. BMC Res Notes. 2011;4(1).

5. Dhillon HK, Singh HJ, Rashidah S, Abdul Manaf H, Nik Mohd Zaki NM. Prevalence of menopausal symptoms in women in Kelantan, Malaysia. Maturitas 2006;54(3):213-21.

6. Unni J. Third consensus meeting of Indian Menopause Society (2008): A summary. J Midlife Health. 2010;1(1):43-7.

7. Garratt A, Schmidt L, MacKintosh A, Fitzpatrick R. Quality of life measurement: bibliographic study of patient-assessed health outcome measures. Bri Med J. 2002;324:1417-21.
8. WHO 2001. The WHO international classification of function (ICF). Press Release WHO/48, Geneva, 15 November.

9. World Health Organisation (WHO). Scientific Group on Research on the Menopause. Geneva: WHO. 1990:866.

10. Lee Y, Kim H. Relationship between menopausal symptoms, depression, and exercise in middle aged women. Int J Nurs Studies. 2008;45:1816-22.

11. Kakkar V, Kaur D, Chopra K, Kaur A, Kaur IP. Assessment of the variation in menopausal symptoms with age, education and working/nonworking status in North-Indian sub population using menopause rating scale (MRS). Maturitas. 2007;57:306-14.

12. Del Prado M, Fuenzalida A, Jara D, Figueroa R, Flores D, Blumel JE. Assessment of quality of life using the Menopause Rating Scale in women aged 40 to 59 years Rev Med Chil. 2008;136:1511-7.

13. Joseph N, Nagaraj K, Saralaya V, Nelliyanil M, Rao PJ. Assessment of menopausal symptoms among women attending various outreach clinics in South Canara District of India. J Mid-life Health. 2014;5(2):84-90.

14. Cheng MH, Wang SJ, Wang PH, Fuh JL. Attitudes towards menopause among middle aged women: a community survey in an island of Taiwan. Maturitas. 2005;52:348-55.

15. Hafiz I, Liu J, Eden J. A quantitative analysis of the menopause experience of Indian women living in Sydney. Aust N Z J Obstet Gynaecol. 2007;47:32934.

16. Yanikkerem E, Koltan SO, Tamay AG, Dikayak S. Relationship between women's attitude towards menopause and quality of life. Climacteric. 2012;15:552-62.

Cite this article as: Ramya NR, Gadgi R.

Menopause rating scale: a simple tool for assessment of climacteric symptoms. Int J Reprod Contracept Obstet Gynecol 2020;9:4250-5. 